\title{
Changes in Heart Rate, Blood Pressure, and Pulse Pressure During Apnoeic Attacks in Newborn Babies
}

\author{
DAVID J. GIRLING* \\ From the Neonatal Research Unit, Institute of Child Health, Hammersmith Hospital, London
}

\begin{abstract}
Girling, D. J. (1972). Archives of Disease in Childhood, 47, 405. Changes in heart rate, blood pressure, and pulse pressure during apnoeic attacks in newborn babies. Electrocardiogram, heart rate, blood pressure, and pattern of respiration were recorded continuously in 8 newborn babies having apnoeic attacks. Apnoeic attacks usually occurred without any premonitory changes in respiration, heart rate, or blood pressure. The heart rate usually fell during an apneoic attack and did so after the onset of apnoea. The pulse pressure most commonly rose as the heart rate fell. If the pulse pressure did not rise as the heart rate fell, major resuscitative procedures were often required. A fall in pulse pressure during apnoeic attacks was only seen in severely ill babies and usually only shortly before they died.

It is suggested that the fall in heart rate during apnoea is the direct effect of hypoxia on the heart or a chemoreceptor reflex, and that the rise in pulse pressure is the result of increased filling volume in accordance with Starling's Law.
\end{abstract}

Apnoeic attacks are common in ill, premature babies. They vary a great deal in their severity and frequency; many are self-terminating while others require major resuscitative procedures such as a period of artificial ventilation with or without external cardiac massage (Still, 1923; Boutourline-Young and Smith, 1950; Daily, Klaus, and Meyer, 1969). Clinical observation suggests that they are not homogeneous in their nature, and the aim of the present study was to investigate the sequence of physiological changes during apnoeic attacks by making continuous recordings of respiratory pattern and other physiological variables in babies who were having such attacks.

\section{Methods and Babies Studied}

Clinical details of the babies studied are summarized in Table I. 5 babies, of whom 2 died, had respiratory distress; 1 died of an intraventricular haemorrhage but did not have respiratory distress; 1 died as a result of total anomalous pulmonary venous drainage and was also found to have microgyria at necropsy; and 1 was previable. They were all receiving oxygen therapy and had umbilical arterial catheters in place for blood gas monitoring. Respiratory distress was diagnosed

Received 1 October 1971.

«Percy J. Neate Research Fellow of the Company of Clothworkers.

Present address: MRC Tuberculosis and Chest Diseases Unit, Brompton Hospital, London SW3 $6 \mathrm{HP}$. if at the age of 4 hours at least 2 of the following signs were present: inspiratory recession, grunting expiration, or a respiratory rate of 60 a minute or more. In those that died hyaline membranes were found at necropsy.

The babies were studied for periods ranging from 108 to 285 minutes continuously. All were studied for at least 120 minutes with the exception of Case 6 who died during the study. The following records were traced: ECG, recorded from standard limb leads; heart rate, computed by a Devices instantaneous rate-meter either from the ECG or from the blood pressure trace; pattern of respiration, recorded from an impedance pneumogram using an Air Shields apnoea monitor; and blood pressure, recorded from a saline-filled Type 4-327-L221 Bell and Howell pressure transducer attached to an umbilical arterial catheter. The pressure recording system was calibrated against a mercury column at each study. All the variables were traced continuously on a Devices 8 channel recorder.

In addition to the continuous records made as described, intermittent measurements of arterial blood gases and $p \mathrm{H}$ were made on all babies, the Fro, was adjusted to maintain $\mathrm{PaO}_{2}$ between 60 and $90 \mathrm{mmHg}$, and intravenous bicarbonate or THAM was given to maintain arterial $\mathrm{pH}$ within acceptable limits. Since the continuous recording of arterial blood gases is not yet technically possible, information about the relation between apnoeic attacks and blood gas changes was not obtained and this is therefore not discussed further.

An apnoeic attack was defined as a period of apnoea lasting 30 seconds or longer. 
Clinical Details of 8 Babies in Study

\begin{tabular}{|c|c|c|c|c|c|c|c|}
\hline $\begin{array}{l}\text { Case } \\
\text { No. }\end{array}$ & Sex & $\begin{array}{c}\text { Gestational } \\
\text { Age } \\
\text { in } \\
\text { Weeks }\end{array}$ & $\begin{array}{c}\text { Birthweight } \\
\text { (g) }\end{array}$ & Diagnosis * & $\begin{array}{l}\text { Age } \\
\text { Studied } \\
\text { (hr) }\end{array}$ & $\begin{array}{c}\text { Number } \\
\text { of Apnoeic } \\
\text { Attacks } \\
\text { During Study }\end{array}$ & Outcome \\
\hline $\begin{array}{l}1 \\
2 \\
3 \\
4 \\
5\end{array}$ & $\begin{array}{l}\mathbf{M} \\
\mathbf{M} \\
\mathbf{M} \\
\mathbf{F} \\
\mathbf{M}\end{array}$ & $\begin{array}{l}28 \\
28 \\
30 \\
25 \\
35\end{array}$ & $\begin{array}{r}1110 \\
880 \\
1360 \\
780 \\
2480\end{array}$ & $\begin{array}{l}\text { RDS } \\
\text { RDS } \\
\text { RDS } \\
\text { Previable } \\
\text { CHD } \\
\quad \text { microgyria }\end{array}$ & $\begin{array}{l}16 \\
34 \\
37 \\
33 \\
24\end{array}$ & $\begin{array}{r}10 \\
2 \\
3 \\
1 \\
2\end{array}$ & $\begin{array}{l}\text { Alive } \\
\text { Alive } \\
\text { Alive } \\
\text { Dead } \\
\text { Dead }\end{array}$ \\
\hline $\begin{array}{l}6 \\
7 \\
8\end{array}$ & $\begin{array}{l}\mathbf{M} \\
\mathbf{F} \\
\mathbf{F}\end{array}$ & $\begin{array}{l}35 \\
28 \\
30\end{array}$ & $\begin{array}{l}2510 \\
1020 \\
1040\end{array}$ & $\begin{array}{l}\text { RDS } \\
\text { IVH } \\
\text { RDS }\end{array}$ & $\begin{array}{l}17 \\
48 \\
20\end{array}$ & $\begin{array}{r}5 \\
19 \\
9\end{array}$ & $\begin{array}{l}\text { Dead } \\
\text { Dead } \\
\text { Dead }\end{array}$ \\
\hline
\end{tabular}

${ }^{\star} \mathrm{RDS}=$ respiratory distress syndrome; $\mathrm{CHD}=$ congenital heart disease; $\mathrm{IVH}=$ intraventricular haemorrhage.

\section{Results}

The 8 babies had 51 apnoeic attacks during these studies. The number recorded in each baby is shown in Table I.

Changes presaging apnoeic attacks. In only 4 of the 51 apnoeic attacks recorded were any changes seen before the onset of apnoea. On these 4 occasions the heart rate started to fall before the onset of apnoea and did so during a period of shallow, irregular respiration and cyanosis which preceded total apnoea. The fall in heart rate was sometimes considerable: from 160 to 125 a minute in Case 6, from 140 to 100 a minute in Case 7, and from 145 to 125 and 145 to 90 a minute in Case 8. The heart rate then continued to fall during the subsequent apnoea. In all the other apnoeic attacks the attack started without any preceding changes in respiration, heart rate, or blood pressure.

Changes in heart rate during apnoea. In 41 of the 51 apnoeic attacks the heart rate fell by at least 10 beats a minute during the attack. In the other 10 it remained unchanged except in 4 attacks which occurred during periodic respiration, when it rose (see below). Of the 41 attacks associated with a fall in heart rate, in 4 the fall started before the onset of apnoea. In the other 37 the heart rate fell after the onset of apnoea and rose again rapidly once the attack had ended.

Changes in blood pressure and pulse pressure during apnoea. Changes in blood pressure and pulse pressure were usually only seen if the heart rate also changed. In 24 attacks the fall in heart rate was accompanied by a concomitant rise in pulse pressure. This rise was usually due to an increase in systolic pressure but was sometimes due to a fall in diastolic, or both. This type of response is illustrated in Fig. 1. On only 2 occasions was an increase in pulse pressure during apnoea seen in the absence of any obvious fall in heart rate. This is illustrated in Fig. 2. In this record there was a considerable increase both in pulse pressure and in systolic and diastolic pressures during apnoea without any significant overall fall in the heart rate.

In 11 apnoeic attacks, though the heart rate fell during the attack, there was no change in the pulse pressure. This type of response is illustrated in Fig. 3. Here, though there was a clear fall in the heart rate during apnoea, there was no consistent

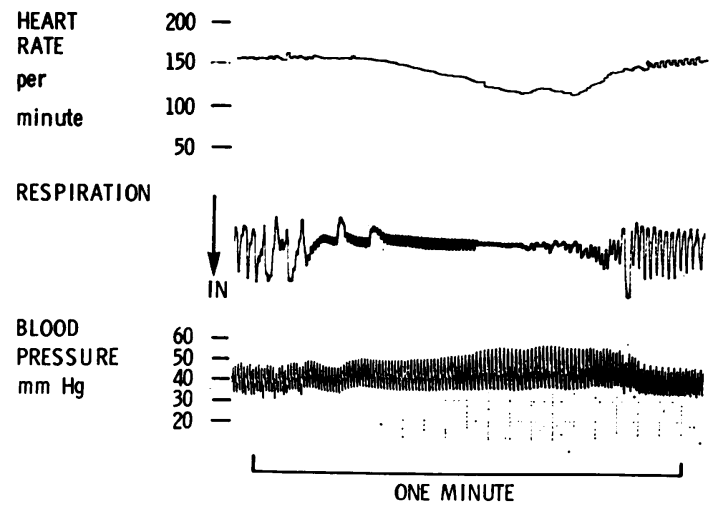

Fig. 1.-Case 3. Changes in heart rate and pulse pressure most commonly seen during an apnoeic attack. After onset of apnoea the heart rate fell and the pulse pressure rose. Both returned rapidly to their previous values once the attack had ended. (In the impedance pneumogram the heart rate is superimposed on the respiratory trace and becomes more obvious during the period of apnoea.) 


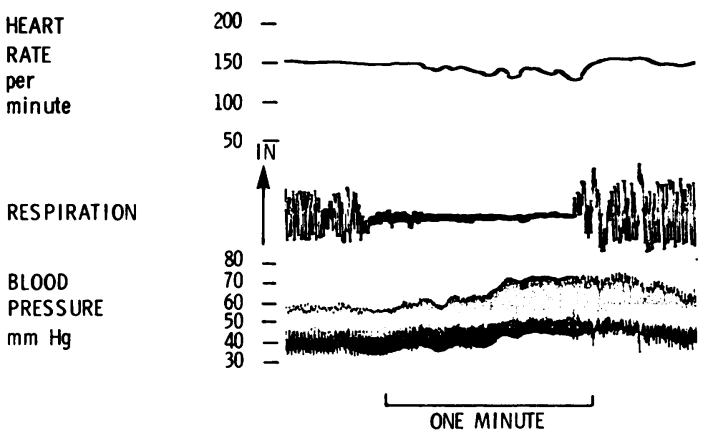

Fig. 2.-Case 5. Showing marked increase in pulse pressure and systolic and diastolic pressures during apnoea unaccompanied by any significant change in heart rate (in this instance the heart rate wavered between 150 and 125 per minute during apnoeic attack without showing any consistent change).

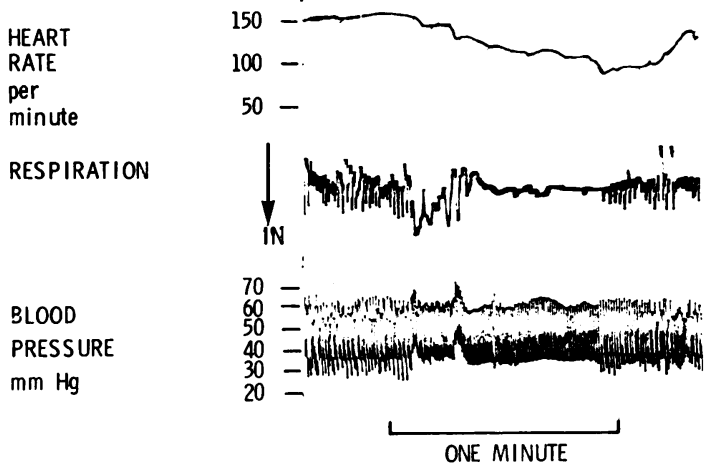

FIG. 3.-Case 6. Showing fall in heart rate during apnoeic attack unaccompanied by any consistent changes in pulse pressure or systolic pressure.

change either in the pulse pressure or in the systolic blood pressure.

In 8 apnoeic attacks the fall in heart rate was accompanied by an overall fall in pulse pressure, though there was sometimes a transient initial rise. This type of response was only seen in 3 severely ill babies (Cases 1, 6, and 7) and in 2 of them only shortly before they died. It is illustrated in Fig. 4 and 5 . In Fig. 4 apnoea was preceded by a period of shallow respiration and variable heart rate; during apnoea there was a fall in systolic pressure and pulse pressure. Fig. 5 shows a similar attack recorded later from the same baby. Here the bradycardia was severe and progressive in spite of 2 periods of external cardiac massage, and pulse pressure and blood pressure fell catastrophically. The pulse pressure was so low (4

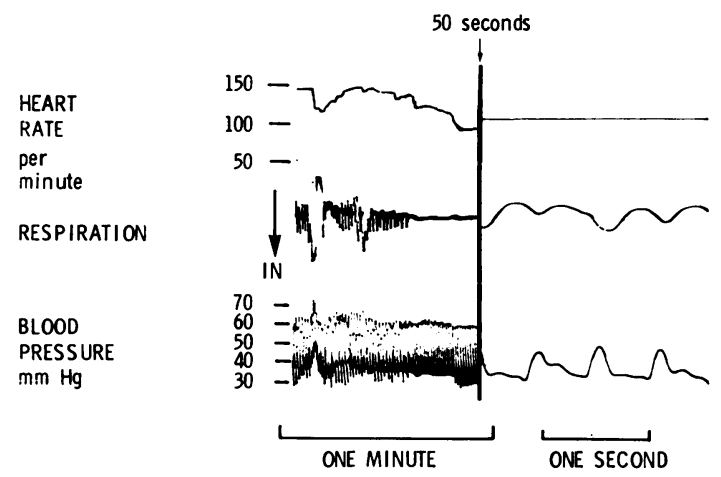

FIG. 4.-Case 6. Showing fall in pulse pressure with fall in heart rate during apnoeic attack. Respiration had just started again in the right-hand side of Fig. A change in paper speed was made during the record and there was an interval of 50 seconds between the 2 parts of the trace shown.

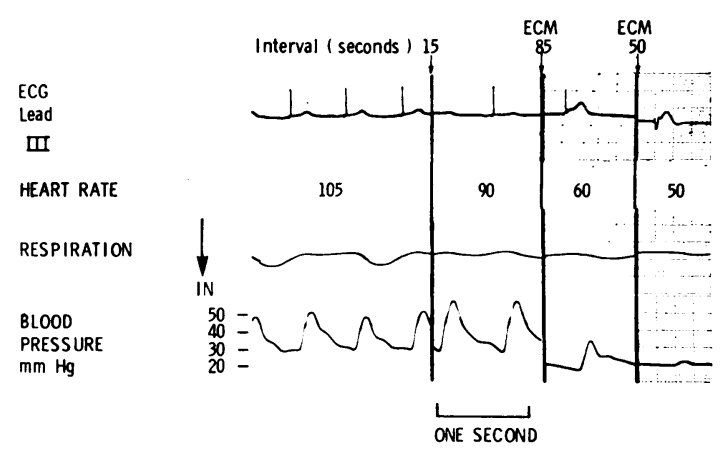

FIG. 5.-Case 6. Showing initial rise in pulse pressure during apnoeic attack, followed by a fall. The fall in pulse pressure and bradycardia was progressive and severe in spite of 2 periods of external cardiac massage (ECM). ECG changes occurred during this attack and at the end of it; though heart rate was still 50 per minute, pulse pressure was very low. The Fig. covers a total period of 150 seconds, with delays of, respectively, 15, 85, and 50 seconds between the 4 parts of the trace.

$\mathrm{mmHg}$ ) at the end of this attack that cardiac output must have been negligible. Resuscitation was successful on this occasion but the baby had a similar attack shortly afterwards from which he did not recover.

Changes during periodic respiration. Fig. 6 shows the changes in heart rate, blood pressure, and pulse pressure which were seen during periodic respiration. During the apnoeic phases the heart rate rose and then fell and the pulse pressure and 
systolic pressure did the same. The apnoeic phases were not usually long enough to come under the definition of an apnoeic attack adopted in this paper, however, on 4 occasions they did last for more than 30 seconds, and when this happened the same pattern of changes in heart rate and blood pressure was seen as was seen during the apnoeic phases of periodic respiration.

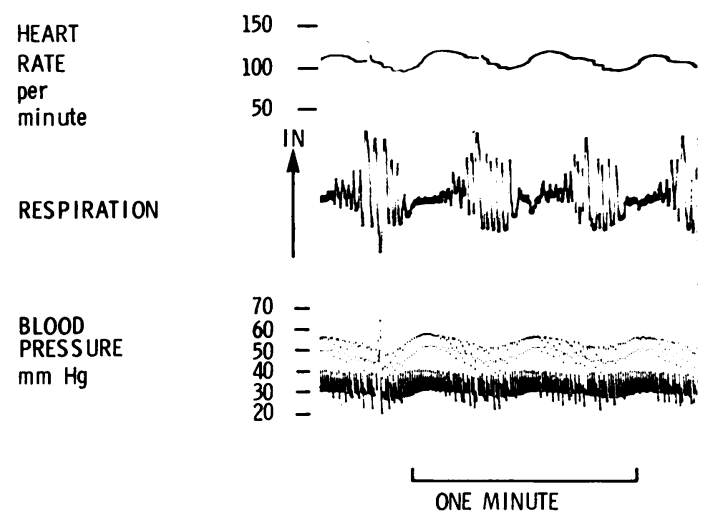

Fig. 6.-Case 7. Showing the changes in heart rate and pulse pressure most commonly seen during periodic respiration. During the respiratory pauses the heart rate and pulse pressure at first rose and then fell, exercising a periodicity out of phase with that of respiration.

Changes related to severity of attack. Assessment of the severity of an apnoeic attack is to some extent subjective. It was attempted by dividing the attacks according to (a) how they ended and (b) how soon after the onset of apnoea the heart rate started to fall. Attacks during which there was no fall in heart rate and attacks during which a fall in heart rate was accompanied by a rise in pulse pressure all ended without major resuscitation being necessary. They either ended spontaneously or after some form of tactile stimulation. Attacks during which a fall in heart rate was accompanied by no change in pulse pressure or by a fall in pulse pressure required major resuscitation on 7 out of 19 occasions. Major resuscitation was defined as a period of artificial ventilation with or without external cardiac massage. It was only given after simple tactile stimulation had failed to end the attack. These findings are summarized in Table II. There was a highly significant difference in the need for major resuscitation in attacks during which a fall in heart rate was or was not accompanied by a rise in pulse pressure $\left(\mathrm{P}<0.001, \chi^{2}\right.$ test).

In the 41 attacks during which there was a fall
TABLE II

Number of Attacks Requiring Major Resuscitation (Artificial Ventilation with or without External Cardiac Massage) in Relation to Changes in Heart Rate and Pulse Pressure Occurring During Attack

\begin{tabular}{l|l|c|c}
\hline $\begin{array}{c}\text { Heart Rate } \\
\text { During } \\
\text { Attack }\end{array}$ & $\begin{array}{l}\text { Pulse Pressure } \\
\text { During Attack }\end{array}$ & $\begin{array}{c}\text { Number of } \\
\text { Attacks Re- } \\
\text { quiring Major } \\
\text { Resuscitation }\end{array}$ & $\begin{array}{c}\text { Total } \\
\text { Number } \\
\text { of } \\
\text { Attacks }\end{array}$ \\
\hline $\begin{array}{l}\text { No change } \\
\text { Fall } \\
\text { Fall }\end{array}$ & $\begin{array}{l}\text { No change or rise } \\
\text { Rise } \\
\text { No change or fall }\end{array}$ & 0 & 6 \\
& Totals & 7 & 22 \\
& & 7 & 47 \\
\hline
\end{tabular}

Note: The 4 attacks which occurred during periodic respiration have been omitted from this Table-they all ended spontaneously.

in heart rate the rate tended to fall earlier in the attacks in which the pulse pressure failed to rise. In Table III the attacks have been divided according to whether the fall in heart rate started within 5 seconds of the onset of apnoea or later than this. Attacks during which the pulse pressure failed to rise differed significantly from the others in the tendency for an earlier fall in heart rate $(P<0.005$, $\chi^{2}$ test).

\section{TABLE III}

Number of Attacks Where Heart Rate Fell Divided According to Whether Fall Started within 5 Seconds of Onset of Apnoea or Later

\begin{tabular}{|c|c|c|c|}
\hline \multirow{2}{*}{$\begin{array}{c}\text { Change in Pulse } \\
\text { Pressure During } \\
\text { Attack }\end{array}$} & \multicolumn{2}{|c|}{$\begin{array}{l}\text { Time Heart Rate } \\
\text { Started to Fall After } \\
\text { Onset of Apnoea }\end{array}$} & \multirow[t]{2}{*}{ Total } \\
\hline & $<5 \mathrm{sec}$ & $>5 \mathrm{sec}$ & \\
\hline $\begin{array}{l}\text { Rise } \\
\text { No change or fall }\end{array}$ & $\begin{array}{l}11 \\
17\end{array}$ & $\begin{array}{r}11 \\
2\end{array}$ & $\begin{array}{l}22 \\
19\end{array}$ \\
\hline Total & 28 & 13 & 41 \\
\hline
\end{tabular}

Note: The timing of the fall in heart rate is shown in relation to the change in pulse pressure which occurred.

Apnoeic attacks during which the fall in heart rate was accompanied by a fall in pulse pressure were only seen in 3 babies, all of whom were very ill at the time they occurred. Of the 3, Case 6 died during the study, another (Case 7) died 2 hours after the study period had ended, and the third (Case 1) was in progressive respiratory failure and required a period of 6 days of artificial ventilation shortly after the study had been completed. He then recovered and has survived. Of the other babies who died but in whom this 
type of attack was not recorded, Case 4 only had one apnoeic attack during this study and apart from his prematurity had no other clinical problems at the time the study was done; Case 5 was never severely ill in the neonatal period but died 2 months later as a result of congenital heart disease, and Case 8 died 3 hours after the end of his study. Of his 9 apnoeic attacks the first 5 all showed a rise in pulse pressure during the fall in heart rate, but 3 of the last 4 showed no change in pulse pressure in spite of a fall in heart rate, suggesting that there was progressive failure of the pulse pressure to rise during bradycardia, though it was never recorded as actually having fallen.

\section{Discussion}

In this paper the changes in heart rate, blood pressure, and pulse pressure which occur during apnoeic attacks in ill, premature babies have been described. In most babies the apnoeic attack occurs without any premonitory changes in respiration, heart rate, or blood pressure; the heart rate falls during the attack and there is a concomitant rise in the pulse pressure; both heart rate and pulse pressure return rapidly to their previous levels once the attack has ended.

The fall in heart rate which occurs might be due to the direct effect of hypoxia on the heart. Bauer (1938) found that acute asphyxia in the newborn rabbit caused a fall in the heart rate which was not vagal. It might therefore have been due to the direct effect of hypoxia on the heart. Alternatively, the fall in heart rate might be due to chemoreceptor reflexes. The presence of well-developed chemoreceptor responses has now been well demonstrated both in preterm animals of various species (Cross and Malcolm, 1952; Born, Dawes, and Mott, 1956; Cassin, Dawes, and Ross, 1964; Purves and Biscoe, 1966; Dawes, 1968), and in term and preterm babies (Cross and Oppé, 1952; Moss, Duffie, and Emmanouilides, 1963; Phillips et al., 1964). If the fall in heart rate and concomitant rise in pulse pressure were a baroreceptor reflex (a rise in blood pressure causing a fall in the heart rate), the rise in pressure should occur before the onset of the fall in heart rate. This was found not to be so; in fact when both heart rate and pulse pressure changed they did so simultaneously. The rise in pulse pressure might be due to vasoconstriction in the pulmonary vascular bed of unventilated lungs in response to hypoxia; however, this would not explain the fall in heart rate. Moreover, in the animals in which such pulmonary vascular constriction has been shown the heart rate usually rose (Born, Dawes, and Mott, 1955).
Hypoxic stimulation of the carotid body chemoreceptors can cause reflex bradycardia. This reflex has been shown in the dog (Bernthal, Greene, and Revzin, 1951; Daly and Daly, 1957; Daly and Scott, 1958, 1959; Daly and Daly, 1959). Hypoxic stimulation of the isolated, perfused carotid bodies produces slowing of the heart provided that the dog is on controlled artificial ventilation. This cardiac slowing is independent of carotid sinus or systemic arterial pressures. An observation of particular interest in the present context is that in the spontaneously breathing dog chemoreceptor stimulation frequently produces an increase in heart rate rather than a slowing, and Daly and Scott (1958) have shown that this is at least partly due to a secondary reflex arising from the lungs, since it occurs during the increased ventilation associated with hypoxia and is reduced by denervation of the lungs. In the apnoeic baby no such pulmonary reflex could operate because respiratory movements are absent and the primary reflex slowing of the heart could therefore take place unmasked by this secondary reflex. Further support for this possibility comes from the work of Davis (1961) on experimental asphyxia in the newborn rabbit. He found that there was an immediate increase both in mean arterial pressure and in the heart rate during the intense dyspnoea associated with the onset of acute anoxia, but that once the animal had become apnoeic the heart rate and the blood pressure fell. It is possible that the chemoreceptor reflex tending to produce a fall in heart rate was masked by a reflex from the lungs producing a rise in heart rate during acute dyspnoea.

Whether the fall in heart rate during the apnoeic attacks reported in this paper was due to a chemoreceptor reflex, to the direct effect of hypoxia on the heart, or to both must at present remain a matter for speculation, but whatever the mechanism of the fall in heart rate, it seems that the most plausible explanation for the rise in pulse pressure is that the fall in heart rate leads to a simultaneous increase in filling volume and so to an increase in stroke volume and pulse pressure in accordance with Starling's Law (Starling, 1918).

The rise in pulse pressure during the fall in heart rate of apnoeic attacks appears to be a means whereby the stroke volume is increased and cardiac output maintained. It is only in the very ill baby that this mechanism breaks down and cardiac output falls catastrophically.

I should like to thank Professor J. P. M. Tizard, Dr. J. W. Scopes, and Professor K. W. Cross for their interest and help, the Company of Clothworkers for their 
grant, and the trustees of the Sir William Coxen Trust Fund for the provision of laboratory space and equipment.

\section{REFERENCES}

Bauer, D. J. (1938). The effect of asphyxia upon the heart rate of rabbits at different ages. Fournal of Physiology, 93, 90 .

Bernthal, T., Greene, W., Jr., and Revzin, A. M. (1951). Role of carotid chemoreceptors in hypoxic cardiac acceleration. Proceedings of the Society of Experimental Biology and Medicine, 76, 121.

Born, G. V. R., Dawes, G. S., and Mott, J. C. (1955). The viability of premature lambs. Fournal of Physiology, 130191.

Born, G. V. R., Dawes, G. S., and Mott, J. C. (1956). Oxygen lack and autonomic nervous control of the foetal circulation in the lamb. Fournal of Physiology, 134, 149.

Boutourline-Young, H. J., and Smith, C. A. (1950). Respiration of full term and of premature infants. American fournal of Diseases of Children, 80, 753.

Cassin, S., Dawes, G. S., and Ross, B. B. (1964). Pulmonary blood flow and vascular resistance in immature foetal lambs. Journal of Physiology, 171, 80.

Cross, K. W., and Malcolm, J. L. (1952). Evidence of carotid body and sinus activity in new-born and foetal animals. fournal of Physiology, 118, 10P.

Cross, K. W., and Oppe, T. E. (1952). The effect of inhalation of high and low concentrations of oxygen on the respiration of the premature infant. Fournal of Physiology, 117, 38.

Daily, W. J. R., Klaus, M., and Meyer, H. B. P. (1969). Apnea in premature infants. Pediatrics, 43, 510 .

Daly, I. de B., and Daly, M. de B. (1957). The effects of stimulation of the carotid body chemoreceptors on pulmonary vascular resistance in the dog. fournal of Physiology, 137, 436.
Daly, I. de B., and Daly, M. de B. (1959). The effects of the carotid body chemoreceptors on the pulmonary vascular bed in the dog. Fournal of Physiology, 148, 201.

Daly, M. de B., and Scott, M. J. (1958). The effect of stimulation of the carotid body chemoreceptors on heart rate in the dog. fournal of Physiology, 144, 148.

Daly, M. de B., and Scott, M. J. (1959). The effect of hypoxia on the heart rate of the dog with special reference to the contribution of the carotid body chemoreceptors. Fournal of Physiology, $145,440$.

Davis, J. A. (1961). The effect of anoxia in new-born rabbits. fournal of Physiology, 155, 56P.

Dawes, G. S. (1968). Foetal and Neonatal Physiology, p. 97. Year Book Medical Publishers, Chicago.

Moss, A. J., Duffie, E. R., Jr., and Emmanouilides, G. (1963). Blood pressure and vasomotor reflexes in the newborn infant. Pediatrics, 32, 175.

Phillips, S. J., Agate, F. J., Jr., Silverman, W. A., and Steiner, P. (1964). Autonomic cardiac reactivity in premature infants. Biologia Neonatorum, 6, 225.

Purves, M. J., and Biscoe, T. J. (1966). Development of chemoreceptor activity. British Medical Bulletin, 22, 56.

Starling, E. H. (1918). The Linacre Lecture on the Law of the Heart, Cambridge, 1915. Longmans, London.

Still, G. F. (1923). Attacks of arrested respiration in the new-born. Lancet. 1, 431.

Correspondence to Dr. D. J. Girling, MRC Tuberculosis and Chest Diseases Unit, Brompton Hospital, Fulham Road, London SW3 6HP. 